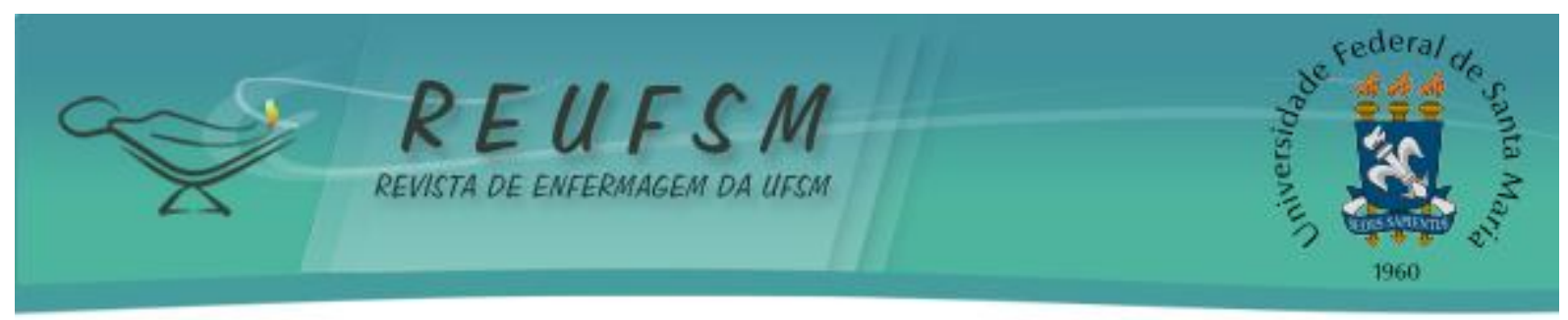

ARTIGO ORIGINAL

\title{
ACIDENTES OCUPACIONAIS COM MATERIAIS PERFUROCORTANTES ENTRE OS TRABALHADORES DO SERVIÇO DE LIMPEZA
}

\section{OCCUPATIONAL ACCIDENTS WITH SHARP TOOLS AMONG CLEANING WORKERS \\ ACCIDENTES DE TRABAJO CON MATERIALES PUNZANTES-CORTANTES EN TRABAJADORES DEL SERVICIO DE LIMPIEZA}

Doi: $10.5902 / 2179769214612$

Silmara Meneguin ${ }^{1}$

Renata Morine ${ }^{2}$ Jairo Aparecido Ayres ${ }^{3}$

RESUMO: Objetivo: analisar o perfil dos acidentes com materiais perfurocortantes ocorridos entre os trabalhadores do serviço de limpeza, de um hospital de ensino do interior de São Paulo. Método: estudo retrospectivo em que se utilizou para a coleta dos dados 377 fichas de Comunicação de Acidente de Trabalho, notificadas por trabalhadores terceirizados do serviço de limpeza de hospital universitário do interior de São Paulo, no período de janeiro de 2000 a dezembro de 2008. Resultados: foram registrados 184 acidentes, média de 1,70 por mês, predominantemente em mulheres $(89,6 \%)$, na faixa etária de 21 a 39 anos $(69 \%)$, principalmente nas enfermarias $(39,7 \%)$, no período diurno $(75,4 \%)$ e com agulhas $(65,3 \%)$. Conclusão: esses achados reforçam não somente a necessidade da implementação de programas eficazes na prevenção de acidentes com materiais perfurocortantes, mas também valorização dos fatores individuais e institucionais envolvidos no processo, a fim de assegurar práticas hospitalares mais seguras.

Descritores: Saúde do trabalhador; Acidentes de trabalho; Serviço hospitalar de limpeza; Riscos ocupacionais.

ABSTRACT: Aim: to analyze the profile of accidents with sharp tools involving cleaning workers at a university hospital in a city of São Paulo. Method: retrospective study in which 377 Occupational Accident reporting forms were used for the data collection, reported by outsourced cleaning workers at a university hospital in a city in the State of São Paulo, between January 2000 and December 2008.Results: 184 accidents were reported, an average of 1.70 per month, predominantly involving women (89.6\%), between 21 and 39 years of age (69\%). The highest incidence was registered at the nursing wards (39.7\%), during the day (75.4\%) and mainly with needles (65.3\%). Conclusions: these findings underline not only the need to implement effective prevention programs for accidents involving sharp tools, but also to recognize individual and institutional factors involved in the process, in order to guarantee safer hospital practices.

Descriptors: Occupational health; Accidents occupational; Housekeeping hospital; Occupational risks.

RESUMEN: Objetivo: analizar el perfil de los accidentes con materiales punzantescortantes entre trabajadores del servicio de limpieza, de empresa subcontratada, de hospital de enseñanza del interior de São Paulo. Método: estudio retrospectivo en que se

\footnotetext{
${ }^{1}$ Enfermeira. Doutora em Ciências. Curso de Enfermagem, Faculdade de Medicina de Botucatu. São Paulo, SP, Brasil. E-mail: silmeneguin@fmb.unesp.br

2 Enfermeira. Hospital das Clínicas, Faculdade de Medicina de Botucatu. São Paulo, SP, Brasil. E- mail: renatamorine@yahoo.com.br

${ }^{3}$ Enfermeiro. Doutor em Doenças Tropicais. Curso de Enfermagem, Faculdade de Medicina de Botucatu. São Paulo, SP, Brasil. E-mail: ayres@fmb.unesp.br
} 


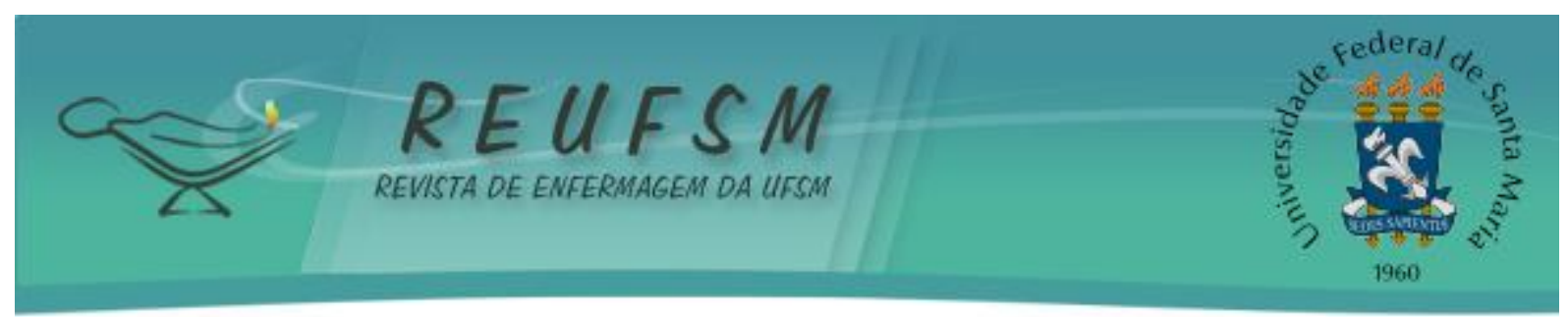

utilizó 377 fichas para recolecta de datos de comunicación de accidente de trabajo, notificadas por trabajadores tercerizados del servicio de limpieza de hospital universitario del interior de São Paulo entre enero del 2000 y diciembre del 2008. Resultados: se registraron 184 accidentes, promedia de 1,70 al mes, sobretodo en mujeres $(89,6 \%)$, entre 21 y 39 años (69\%), en las enfermerías $(39,7 \%)$, durante el día $(75,4 \%)$ y con agujas $(65,3 \%)$. Conclusiones: estos resultados refuerzan no sólo la necesidad de implementación de programas eficaces de prevención de accidentes con materiales punzantes-cortantes, pero también la valorización de los factores individuales e institucionales que intervienen en el proceso, lo que garantizaría la seguridad de los servicios hospitalarios.

Descriptores: Salud laboral; Accidentes de trabajo; Servicio de limpieza en hospital; Riesgos laborales.

\section{INTRODUÇÃO}

As instituições de saúde são locais considerados tipicamente insalubres, na medida em que expõem os profissionais que prestam serviço nestes ambientes a inúmeros riscos ocupacionais. ${ }^{1}$ Dentre estes, destacam-se os acidentes de trabalho com material biológico, possivelmente contaminado. ${ }^{2}$

O contato diário com estes materiais aumenta o risco de acidentes dessa natureza, muitas vezes provocados por deficiência técnica, não adesão às normas de biossegurança, déficit de informação, sobrecarga de trabalho e condições laborais inadequadas. ${ }^{3-4}$

Outro fator relevante que contribui para esse tipo de acidente são as atitudes errôneas dos profissionais de saúde, que podem atingir outros profissionais, atuantes em atividades de apoio no âmbito hospitalar, como é o caso dos trabalhadores do serviço de limpeza. ${ }^{5}$ Embora estes não desempenhem atividades assistenciais, podem se tornar vítimas e serem acometidos direta ou indiretamente por lesão corporal e/ou doenças que podem causar morte, perda ou redução da capacidade de trabalho.

Neste contexto, o surgimento da Síndrome de Imunodeficiência Adquirida (AIDS) com a possível transmissão ocupacional do vírus do HIV, decorrente de acidentes de trabalho com material biológico, despertou na década de 80 preocupação de entidades internacionais com a higiene e segurança no trabalho. ${ }^{6}$ A publicação do "Guia para prevenção da transmissão do HIV, vírus da hepatite B nos profissionais de saúde", pelo Centers for Disease Control and Prevention (CDC) instituía a utilização de precauções universais, denominadas posteriormente de padrões, toda vez que se suspeitava ou conhecia o agente infeccioso. ${ }^{6}$

Estas recomendações contemplavam o uso dos equipamentos de proteção individual sempre que fosse previsto o contato com sangue, líquido amniótico, cerebroespinhal, pericárdico, peritonial, pleural e sinovial, além de outros fluidos corporais, independente da situação sorológica do paciente. ${ }^{7}$

No entanto, muitos trabalhadores, apesar de acolherem as normas de biossegurança, estas ainda não permeiam a prática diária com a mesma intensidade, devido ao sentimento de invulnerabilidade dos mesmos. ${ }^{8}$

Fato preocupante, pois estima-se que a possibilidade de infecção de uma pessoa, quando se expõe ao HIV ao se acidentar com uma agulha contaminada, é de aproximadamente 1 em 250 casos; por outro lado, quando se expõe dessa mesma forma ao vírus da Hepatite $B$, a probabilidade é mais alta: de 1 em 7 casos. ${ }^{9}$

Face aos riscos a que trabalhadores do serviço de limpeza estão expostos, considerou-se relevante a realização dessa pesquisa, no intuito de conhecer a magnitude dos acidentes ocorridos nesta instituição e também fornecer subsídios para implementação 


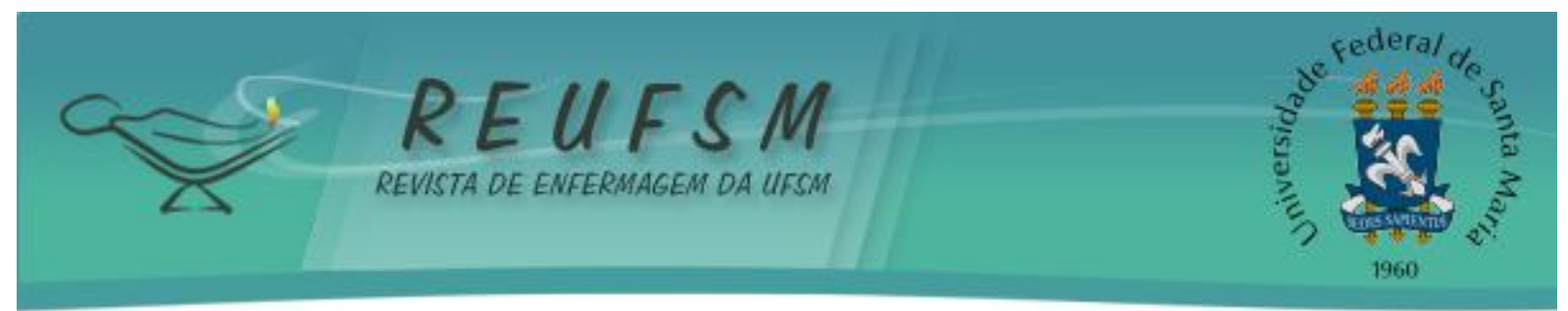

de protocolos de biossegurança, com intuito de minimizar e/ou evitar os acidentes ocupacionais com material perfurocortante.

Frente ao exposto, esta pesquisa busca responder: Quais são as características dos acidentes com materiais perfurocortantes ocorridos entre os trabalhadores do serviço de limpeza de um hospital do interior de São Paulo?

Para tanto, objetiva-se: analisar o perfil dos acidentes com materiais perfurocortantes ocorridos entre os trabalhadores do serviço de limpeza, de um hospital de ensino do interior de São Paulo.

\section{MÉTODO}

Estudo retrospectivo, descritivo, exploratório, com abordagem quantitativa. A coleta dos dados foi realizada nos meses de março a julho de 2009, mediante levantamento de 377 fichas de Comunicação de Acidente de Trabalho (CAT), notificadas pelos trabalhadores terceirizados do serviço de limpeza de hospital universitário do interior de São Paulo, no período de janeiro de 2000 a dezembro de 2008.

A referida instituição é credenciada para atendimento de pacientes de diversas especialidades, provenientes do Sistema Único de Saúde (SUS) e com abrangência do Departamento Regional de Saúde Bauru - São Paulo (DRS-6). Destaca-se também pelas atividades assistenciais, de ensino e de pesquisa. Em consonância com a legislação possui Comissão de Gerenciamento de Resíduos de Serviços de Saúde, Comissão Interna de Prevenção de Acidentes (CIPA) e Serviço Especializado em Engenharia de Segurança e Medicina do Trabalho (SESMT).

Considerando o objetivo da pesquisa, destacam-se como critério de inclusão as fichas referentes aos acidentes com materiais perfurocortantes; e de exclusão, as notificações que não possuíam informações complementares sobre a ocorrência, a destacar: sexo, idade, locais do corpo acometido e período de ocorrência do evento.

Para a coleta de dados elaborou-se formulário constituído de duas partes, sendo a primeira de dados de identificação e a segunda de informações referentes ao acidente. Os dados foram armazenados em banco de dados no Microsoft Excel, processados no programa Statistical Package for the Social Sciencies (SPSS) 15.0 for Windows, e por fim categorizados e apresentados em frequências absolutas e relativas.

Estudo aprovado pelo Comitê de Ética em Pesquisa da instituição, sob número 3234/2009. A confidencialidade dos dados foi respeitada em conformidade com a Resolução 466/12 ${ }^{10}$ do Conselho Nacional de Saúde do Ministério da Saúde, que regulamente a pesquisa com seres humanos no país.

\section{RESULTADOS}

Durante o período estudado foram registradas 377 fichas de CAT. Destas, foram selecionadas 190 referentes aos acidentes com materiais perfurocortantes e excluídas seis que não atendiam aos critérios de inclusão. Logo, foram computados $184(48,8 \%)$ acidentes envolvendo materiais perfurocortantes, entre os trabalhadores do serviço de limpeza hospitalar, o que representa uma média de 1,70 por mês, sendo predominantemente em mulheres $(89,6 \%)$, na faixa etária de 21 a 39 anos (69\%), Tabela 1.

Outro dado relevante observado refere-se ao fato da maioria dos registros ter ocorrido entre 2002 e 2005, período anterior à implantação da Norma Regulamentadora 32 (NR32), que estabelece as diretrizes para a implementação de medidas de proteção à segurança e à saúde dos trabalhadores dos serviços de saúde, bem como daqueles que exercem atividades de promoção e assistência à saúde em geral. ${ }^{11}$ 


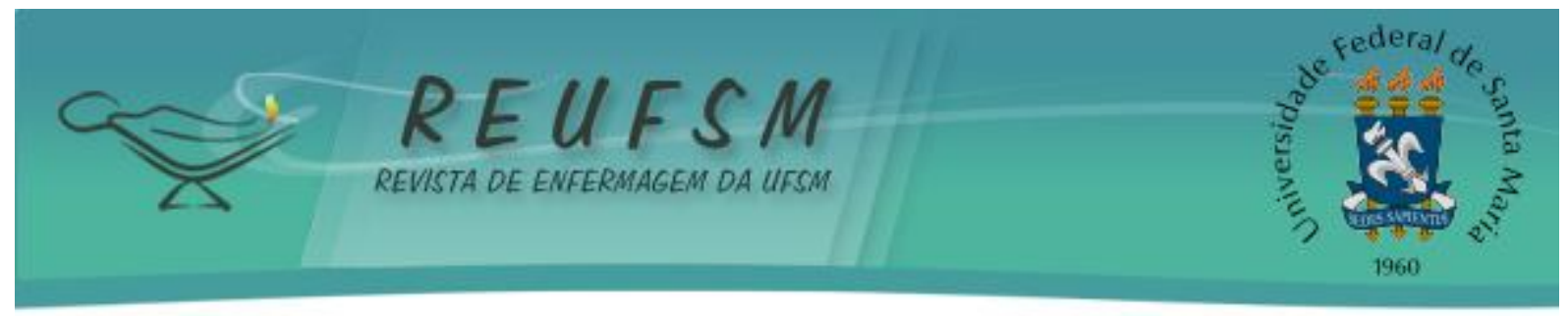

Tabela 1 - Número de acidentes com materiais perfurocortantes, de acordo com sexo e faixa etária. Botucatu, SP, 2000-2008

\begin{tabular}{|c|c|c|c|}
\hline \multicolumn{2}{|c|}{ Variáveis } & n (184) & $\%$ \\
\hline \multirow{2}{*}{ Sexo } & Feminino & 165 & 89,6 \\
\hline & Masculino & 19 & 10,3 \\
\hline \multirow{4}{*}{ Faixa etária } & $\leq 20$ & 1 & 0,54 \\
\hline & $21-39$ & 127 & 69 \\
\hline & $40-59$ & 55 & 29,9 \\
\hline & $60+$ & 1 & 0,54 \\
\hline
\end{tabular}

No que se refere ao local em que os acidentes ocorreram, nota-se que os mesmos foram mais prevalentes nas enfermarias $(39,7 \%)$, especialmente de clinica médica e gastroenterologia e, posteriormente, no pronto socorro (13\%). Não foram encontrados registros dos locais de ocorrência em 24 (13\%) notificações. Quanto ao período, a maior frequência dos acidentes foi verificada no período diurno (75,4\%), Tabela 2.

Tabela 2 - Unidades e período em que ocorreram os acidentes com materiais perfurocortantes. Botucatu, SP, 2000-2008

\begin{tabular}{|c|c|c|c|}
\hline \multicolumn{2}{|c|}{ Unidades /Período } & n (184) & $\%$ \\
\hline \multirow{10}{*}{ Unidades } & Enfermarias & 73 & 39,7 \\
\hline & Pronto Socorro & 24 & 13,0 \\
\hline & Não especificado & 24 & 13,0 \\
\hline & Unidade de Terapia Intensiva & 15 & 8,1 \\
\hline & Laboratórios & 13 & 7,0 \\
\hline & Centro Cirúrgico/ Obstétrico & 12 & 6,5 \\
\hline & Unidade de Hemodiálise & 10 & 5,4 \\
\hline & Ambulatórios & 6 & 3,3 \\
\hline & Hemocentro & 4 & 2,2 \\
\hline & Unidades de diagnóstico & 3 & 1,6 \\
\hline \multirow{3}{*}{ Período } & Matutino & 84 & 45,6 \\
\hline & Vespertino & 55 & 29,9 \\
\hline & Noturno & 45 & 24,5 \\
\hline
\end{tabular}

Dentre os acidentes com material perfurante $(66,9 \%)$ os mais prevalentes foram aqueles com agulhas $(65,3 \%)$. Embora em menor proporção, também foram registradas ocorrências com vidros $(17,9 \%)$ e lâminas $(4,7 \%)$. No que diz respeito à parte do corpo acometida, constatam-se as mãos com $(83,7 \%)$, situação que contribuiu para o afastamento de nove trabalhadores $(4,9 \%)$ - Tabela 3. 


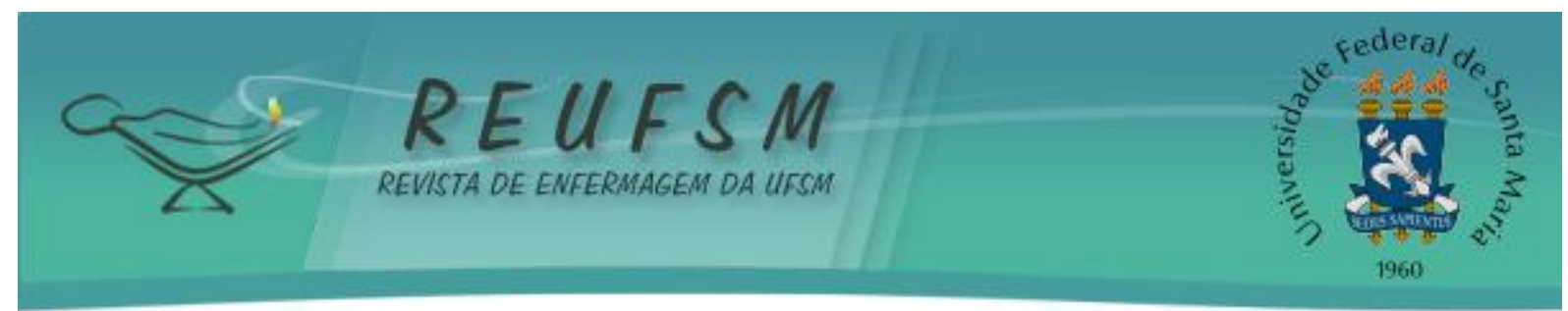

Tabela 3 - Agente causal e local do corpo dos acidentes com materiais perfurocortantes. Botucatu, SP, 2000-2008

\begin{tabular}{|c|c|c|c|}
\hline \multicolumn{2}{|c|}{ Agente causal/local anatômico } & \multirow[t]{2}{*}{$\mathrm{n}(184)$} & \multirow[t]{2}{*}{$\%$} \\
\hline Agente causal & Cortante & & \\
\hline & Vidro & 33 & 17,9 \\
\hline & Lâmina de barbear & 4 & 2,1 \\
\hline & Lâmina de vidro & 3 & 1,6 \\
\hline \multirow{2}{*}{\multicolumn{4}{|c|}{$\begin{array}{l}\text { Lamina de bisturı } \\
\text { Perfurante }\end{array}$}} \\
\hline & & & \\
\hline & Agulha & 120 & 65,3 \\
\hline & Pinça & 3 & 1,6 \\
\hline & Não especificados & 19 & 10,3 \\
\hline \multirow[t]{3}{*}{ Locais do corpo } & Mãos & 154 & 83,7 \\
\hline & Pernas & 28 & 15,2 \\
\hline & Pés & 2 & 1,1 \\
\hline
\end{tabular}

\section{DISCUSSÃO}

O ambiente hospitalar pode ser considerado insalubre à medida que propicia a exposição dos profissionais de diversas categorias aos inúmeros fatores de riscos ocupacionais. Sabe-se que considerável proporção de acidentes são produzidos por materiais perfurocortantes contaminados, envolvendo profissionais dos serviços de apoio, principalmente os da limpeza, durante a coleta de lixo hospitalar. ${ }^{12}$

Em estudo retrospectivo realizado nos serviços de referência da microrregião de Votuporanga-SP, no período de 2001 a 2005, foram identificados 273 acidentes com perfurocortantes, sendo que destes $8,1 \%$ ocorreram com servidores da limpeza. ${ }^{13}$ Dado corroborado em outro estudo realizado na região centro-oeste do país em que do total de acidentes com perfurocortantes $12,4 \%$ ocorreram em profissionais do grupo de apoio, sendo este o terceiro grupo mais prevalente. ${ }^{14}$

A elevada incidência dos acidentes com trabalhadores do serviço de limpeza tem sido cada vez mais discutida por pesquisadores e profissionais da saúde, em virtude de diversos fatores que estão relacionados, não apenas ao desconhecimento ou imprudência dos profissionais da saúde em relação à adoção das medidas de biossegurança (fatores individuais), mas também a fatores institucionais como a falta de capacitação, de recursos humanos, de condições inadequadas de trabalho, sobrecarga laboral, dentre outros. ${ }^{3,6}$

Ainda que, os condicionantes para ocorrência deste tipo de evento estejam atrelados à fatalidade, à culpa pela ocorrência do acidente e à falta de organização do serviço ${ }^{1}$ e o sentimento de invulnerabilidade do trabalhador também contribui para banalização do cuidado consigo e propensão ao acidente de trabalho. ${ }^{8}$

Dado que remete à necessidade de investimento institucional no que diz respeito à identificação dos possíveis riscos no ambiente de trabalho, a intervenções preventivas e de conscientização para uma prática laboral segura.

No que se refere ao local de ocorrência, embora estes acidentes sejam passíveis de ocorrência em qualquer unidade hospitalar, a maioria acontece em unidades de internação $(27 \%)$, terapia intensiva $(13 \%)$ e centro cirúrgico $(25 \%)$, como mostra a literatura. ${ }^{15}$ Resultados que vêm ao encontro do presente estudo, que além das duas primeiras unidades descritas, prevaleceram também os acidentes na unidade de prontosocorro, o que pode ser justificado pela diversidade de procedimentos assistenciais realizados neste local, aliada à complexidade da assistência e dinâmica de trabalho, principalmente em hospitais terciários e de referência regional. 


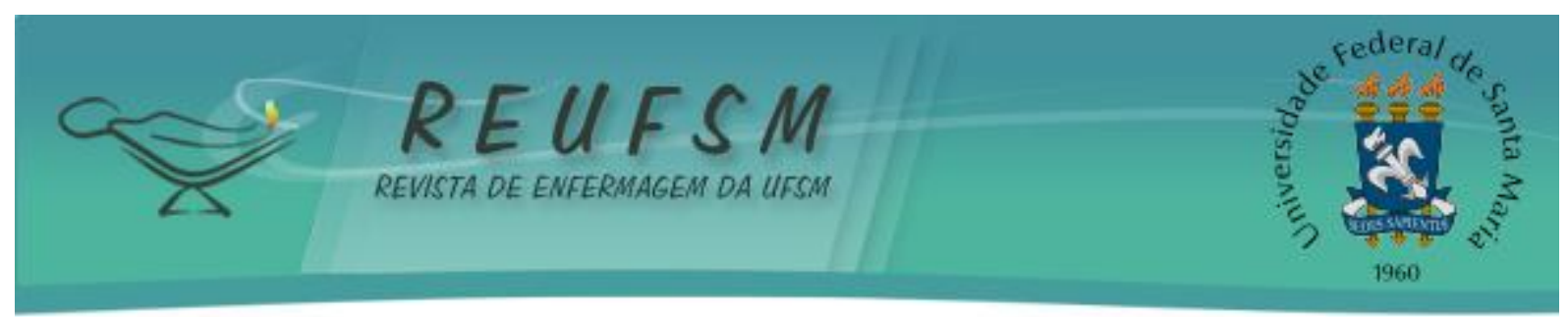

Outro dado de interesse dessa pesquisa foi a prevalência de acidentes em mulheres jovens, dado corroborado em outros estudos que abordam essa temática. ${ }^{13-14} \mathrm{O}$ maior contingente de mulheres exercendo essas atividades pode estar condicionado ao trabalho sem qualificação e necessidade de contribuir para o aumento da renda, o que propicia desgaste físico e emocional expondo-as a maior risco de acidentes ocupacionais. ${ }^{1,5,16}$

Além disso, no contexto dessa pesquisa, há que se considerar que um dos principais fatores que pode ter influenciado a ocorrência de acidentes com material perfurocortantes está atrelado às ações indevidas de profissionais de saúde e acadêmicos, que manipulam este material em suas atividades assistenciais e não realizam o descarte adequado. Fato que pode ser atribuído a indevida conscientização dos riscos envolvidos em suas práticas, para si e para os outros profissionais que compartilham este espaço.

Subterfúgio não justificável frente aos danos graves e reais causados por um acidente com material biológico e com custos diretos e indiretos relacionados ao evento. Outros custos mais difíceis de serem quantificados incluem o emocional, o social e a preocupação sobre as possíveis consequências de uma exposição, além da toxicidade medicamentosa e absenteísmo. ${ }^{15}$

Embora os prejuízos físicos sejam mais facilmente percebidos, sintomas e transtornos psiquiátricos têm sido cada vez mais observados após a ocorrência de um acidente de trabalho. Nesse contexto, o Transtorno de Estresse Pós-Traumático (TEPT) é o evento psicológico mais comum após a experiência de um evento estressor traumático em que as vítimas acabam constantemente revivendo a situação traumática e apresentando reações extremas de ansiedade como se o evento estivesse continuamente ocorrendo. ${ }^{17}$ Transtorno que pode repercutir no nível de satisfação do trabalho, nos índices de absenteísmo, na rotatividade de funcionários, nas licenças para tratamento de saúde e, até mesmo, em aposentadoria adiantada. ${ }^{18}$

Em relação ao afastamento do trabalho, nesta pesquisa, nove trabalhadores foram afastados de suas atividades profissionais. Embora o afastamento seja uma exigência legal, pode ter implicações salariais, além do risco de perder emprego em empresas de iniciativa privada. ${ }^{19}$

Face às implicações decorrentes do acidente de trabalho, a subnotificação do evento pode ocorrer e ser advinda da falta de esclarecimento sobre o registro, como forma de garantir direitos legais, além de servir de instrumento para reivindicações de melhores condições para segurança laboral. Estudo que analisou a incidência de acidentes ocupacionais entre profissionais de saúde atuantes em centro cirúrgico constatou que a subnotificação foi atribuída à irrelevância do acidente, desconhecimento do protocolo de rotina, displicência e sobrecarga de trabalho. ${ }^{20}$

No que se refere ao agente causal do acidente evidenciou-se que foi provocado predominantemente por material tipo perfurante, sendo que as agulhas contribuíram com $65,3 \%$ dos casos, resultado corroborado em estudos envolvendo a mesma problemática em discussão. ${ }^{13,21}$ Estudo realizado em hospital universitário no Brasil em que se analisaram os acidentes de trabalhos evidenciou que mais da metade dos mesmos foram causados por materiais perfurocortantes, dentre estes ocorrências com agulhas e peças cirúrgicas. ${ }^{22}$

Acidentes envolvendo agulhas com lúmen, especialmente aquelas utilizadas para coleta de sangue e inserção de cateter intravascular, são particularmente preocupantes, pois estes contêm sangue residual e estão associados com um risco elevado de transmissão do HIV e hepatite $\mathrm{B}$ e C. ${ }^{23}$ Estudo caso-controle sobre hepatite $\mathrm{C}$ ocupacional mostrou que $\mathrm{o}$ risco de contaminação esteve relacionado com exposições envolvendo agulhas com lúmen e previamente utilizadas em veias ou artérias dos pacientes fonte. ${ }^{24}$

No Brasil, a NR 32, publicada em 2008, em consonância com estas medidas preconiza a obrigatoriedade do uso de materiais perfurocortantes com dispositivo de 


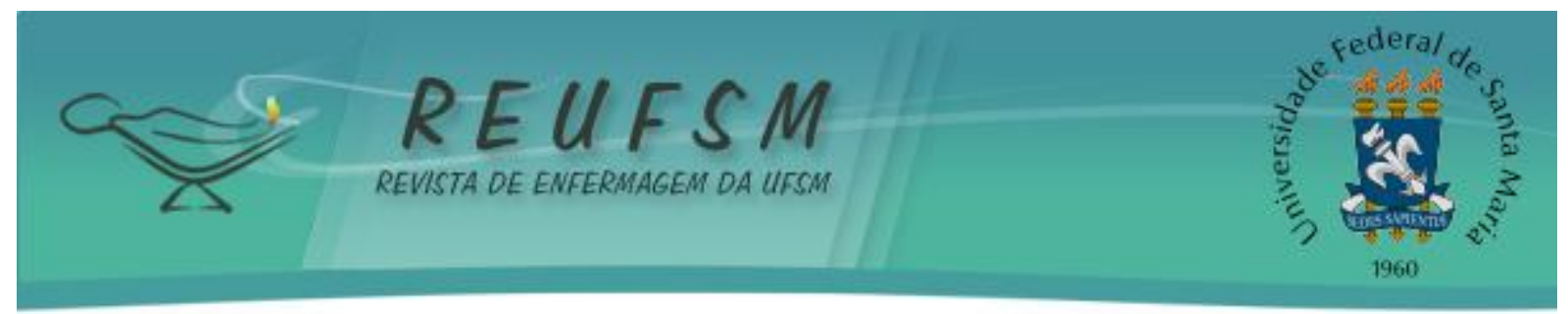

segurança nas instituições hospitalares. ${ }^{11}$ Porém, cabe salientar que nenhum dispositivo de segurança ou estratégia é igualmente efetiva em todos os serviços de saúde. ${ }^{15}$

Tais acidentes ocorrem em decorrência do descarte de agulhas em locais inapropriados, como em lixo comum, mesas de cabeceira ou em recipientes erroneamente adaptados, perfurando, na maioria dos casos, as mãos, durante a limpeza do chão, de mobília e coleta do lixo. Outra possibilidade refere-se ao destino final da caixa coletora de material perfurocortante, que com frequência encontra-se preenchida além de sua capacidade. Saliente-se que, mesmo que o trabalhador do serviço de limpeza utilize o equipamento de proteção individual (EPI), não se descarta a possibilidade de ocorrência do acidente.

É preciso que, além do fornecimento dos EPIs e das informações quanto ao seu uso, seja dedicada uma atenção particularizada a cada trabalhador, enfatizando a importância da adesão às medidas de segurança. As causas dos acidentes não devem ser meramente apontadas para os trabalhadores, mas ao processo de trabalho vivenciado na instituição. Em hospitais de ensino é relevante a responsabilidade dos docentes na formação de acadêmicos comprometidos com as normas de biossegurança e preparados para exercer suas atividades profissionais com ética, responsabilidade e valorização do trabalho interdisciplinar, na construção coletiva de saúde e segurança. ${ }^{25}$

\section{CONSIDERAÇÕES FINAIS}

Constatou-se que agulha e vidro foram os principais materiais envolvidos nos acidentes, ocorridos na sua maioria em enfermarias e pronto-socorro. Resultados que denotam a necessidade não somente de implementação de programas eficazes de prevenção de acidentes com materiais perfurocortantes, mas também em mudança de cultura sobre riscos ocupacionais, considerando-se a magnitude dos fatores individuais e institucionais envolvidos no processo.

O uso correto das medidas de biossegurança perpassa não somente pela provisão do material adequado, mas também pela capacitação, conscientização e valorização das adversidades enfrentadas pelos trabalhadores. Para tanto, é imprescindível a presença das instituições de saúde neste cenário.

Os limites dos resultados do estudo referem-se ao delineamento retrospectivo da pesquisa, em que se utilizam informações previamente registradas sem possibilidade de intervenção. Foi escolhido para a pesquisa porque permitiu descrever as principais variáveis de interesse e sua distribuição, além de agregar conhecimentos inerentes a uma temática pouco abordada na literatura. Ademais, as informações registradas no CAT, nesta instituição, são iniciantes e não refletem a amplitude dos acidentes, em todas as suas dimensões.

\section{REFERÊNCIAS}

1. Balsamo AC, Felli VEA.Estudo sobre os acidentes de trabalho com exposição aos líquidos corporais humanos em trabalhadores da saúde de um hospital universitário. Rev Latinoam Enferm. 2006;14(3):346-53.

2. Patil S, Rao RS, Agarwal A. Awareness and risk perception of hepatitis B infection among auxiliary healthcare work. J Int Soc Prev Community Dent. 2013;3(2):67-71.

3. Barboza DB, Soler ZASG, Ciorlia LAS. Acidentes de trabalho com perfurocortante envolvendo a equipe de enfermagem de um hospital de ensino. Arq Ciênc Saúde. 2004;11(2):93-9.

4. Galon T, Robazzi MLCC, Marziale MHP. Acidentes de trabalho com material biológico em hospital universitário de São Paulo. Rev Eletrônica Enferm. 2008;10(3):673-85. 


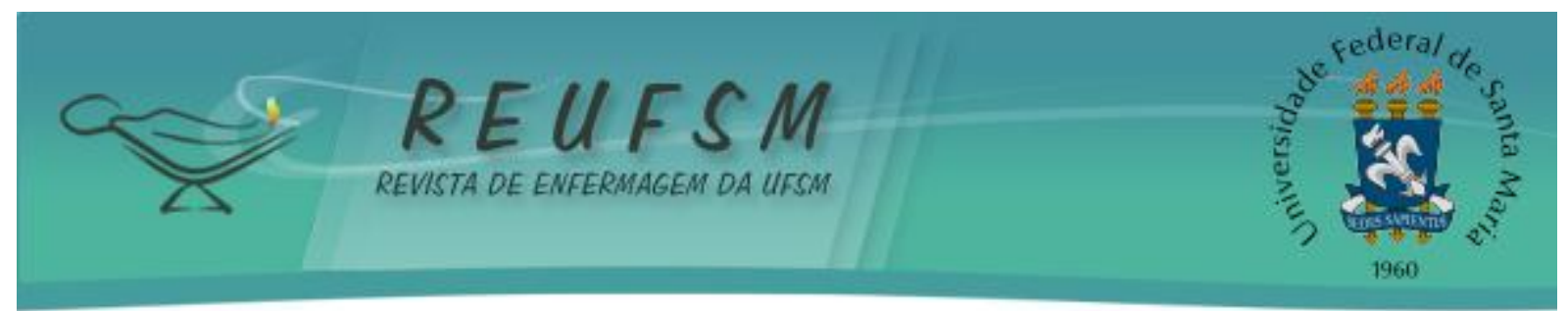

5. Chilida MSP, Cocco MIM. Saúde do trabalhador e terceirização: perfil de trabalhadores de serviço de limpeza hospitalar. Rev Latinoam Enferm. 2004;12(2):271-6.

6. Villarinho MV, Padilha MI. Estratégias de biossegurança dos trabalhadores da saúde no cuidado às pessoas com HIV/AIDS (1986-2006). Esc Anna Nery. 2014;18(1):25-31.

7. Galon T, Marziale MHP, Souza WL. A legislação brasileira e as recomendações internacionais sobre a exposição ocupacional aos agentes. Rev Bras Enferm. 2011;64(1):160-7.

8. Vieira M, Padilha MICS. O HIV e o trabalhador de enfermagem frente ao acidente com material perfurocortante. Rev Esc Enferm USP. 2008;42(4):804-10.

9. Organização Pan-Americana da Saúde (OPAS). Módulos de Princípios de Epidemiologia para o Controle de Enfermidades - Módulo 2: Saúde e doença na população. Brasília (DF): OPA, Ministério da Saúde; 2010.

10. Ministério da Saúde. Conselho Nacional de Saúde. Resolução $n^{\circ} 466$, de 12 de dezembro de 2012. Aprovar as seguintes diretrizes e normas regulamentadoras de pesquisas envolvendo seres humanos. Brasília (DF): Ministério da Saúde; 2012.

11. Brasil. Ministério do Trabalho e Emprego. Gabinete do Ministro. Portaria $n^{\circ} 485$, de 11 de novembro de 2005. Aprova a Norma Regulamentadora $n^{\circ} 32$ - Segurança e Saúde no Trabalho em Estabelecimentos de Saúde. Brasília (DF): Ministério do Trabalho e Emprego; 2005.

12. Alamgir H, Yu S. Epidemiology of occupational injury among cleaners in the healthcare sector. Occup Med. 2008;58(6):393-9.

13. Dias MAC, Machado AA, Santos BMO. Acidentes ocupacionais com exposição a material biológico: retrato de uma realidade. Medicina. 2012;45(1):12-22.

14. Morais NO, Paniago AMM, Negri AC, Oliveira OA, Cunha RV, Oliveira SMVL. Exposição ocupacional com material potencialmente contaminado entre profissionais da área de apoio. Cogitare Enferm. 2009;14(4):709-13.

15. Rapparini C, Reinhardt EL. Manual de implementação do Programa de prevenção de acidentes com materiais perfurocortantes em serviços de saúde. São Paulo: Fundacentro; 2010. Adaptado de Workbook for designing, implementing, and evaluating a sharps injury prevention program of Centers for Disease Control and Prevention (CDC) [Internet]; 2008 [acesso em 2013 jul 3]. Disponível em: http: / / www.riscobiologico.org\&www.fundacentro.gov.br.

16. Ceron MDS. Serviço hospitalar de limpeza e acidentes de trabalho: contribuições da enfermagem [dissertação]. Santa Maria (RS): Universidade Federal de Santa Maria; 2013. $125 \mathrm{p}$.

17. Schaefer LS, Lobo BOM, Kristensen $\mathrm{CH}$. Transtorno de estresse pós-traumático decorrente de acidente de trabalho: implicações psicológicas, socioeconômicas e jurídicas. Estud Psicol (Natal). 2012;17(2):329-36.

18. Hensel J, Bender A, Bacchiochi J, Pelletier M, Dewa CS. A descriptive study of a specialized worker's psychological trauma program. Occup Med (London). 2010;60(8):65457.

19. Ali R, Shaharudin R, Omar A, Yusoff F. Workplace injuries and risk reduction practices in Malaysia. Int J Occup Environ Health. 2012;18(4):299-306. 


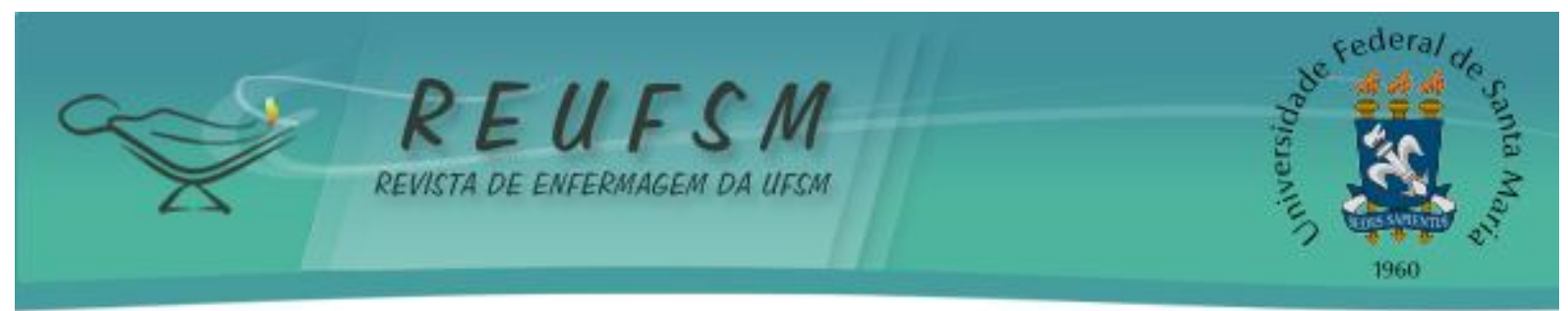

20. Oliveira AC, Gonçalves JA. Acidente ocupacional por material perfurocortante entre profissionais de saúde de um centro cirúrgico. Rev Esc Enferm USP. 2010;44(2):482-7.

21. Ruas EFG, Santos L, Barbosa DA, Belasco AGS, Bettencourt ARC. Acidentes ocupacionais com materiais perfurocortantes em hospitais de Montes Claros-MG. REME Rev Min Enferm. 2012;16(3):437-43.

22. Bakke HA, Araujo NMC. Acidentes de trabalho com profissionais de saúde de um hospital universitário. Produção. 2010;20(4):669-76.

23. Silva TR, Rocha AS, Ayres JA, Juliani CMCM. Acidente com material perfurocortante entre profissionais de enfermagem de um hospital universitário. Rev Gaúcha Enferm. 2010;31(4):615-22.

24. Yazdanpanah $Y$, De carli G, Migueres B, Lot F, Campins M, Colombo C, et al. Risk factors for hepatitis $\mathrm{C}$ virus transmission to health care workers after occupational exposure: a european case-control study. Clin Infect Dis. 2005;41(10):1423-30.

25. Fassini $P$, Hahn GV. Riscos à segurança do paciente em unidade de internação hospitalar: concepções da equipe de enfermagem. Rev Enferm UFSM [Internet]. 2012 [acesso em $2014 \mathrm{fev} \mathrm{10];2(2):290-9.} \mathrm{Disponível} \mathrm{em:} \mathrm{http://cascavel.ufsm.br/revistas/ojs-}$ 2.2.2/index.php/reufsm/article/view/4966/3753.

Data de recebimento: $29 / 06 / 2014$

Data de aceite: 04/03/2015

Contato do autor responsável: Silmara Meneguin

Endereço postal: Faculdade de Medicina de Botucatu - Departamento de Enfermagem -

Distrito de Rubião Jr. s/n - CEP 18618-970

E-mail: silmeneguin@fmb.unesp.br 